\title{
Dermoid Cyst of the Infratemporal Fossa: Case Report and Review of the Literature
}

\author{
Thomas M. Triplett ${ }^{1} \quad$ Adam Griffith $^{1} \quad$ Kimmo J. Hatanpaa ${ }^{2}$ Samuel L. Barnett ${ }^{1}$
}

\author{
${ }^{1}$ Department of Neurological Surgery, University of Texas \\ Southwestern Medical Center, Dallas, Texas, United States \\ 2 Department of Pathology, University of Texas Southwestern Medical \\ Center, Dallas, Texas, United States
}

\begin{abstract}
Address for correspondence Samuel L. Barnett, MD, Associate Professor, Department of Neurological Surgery, University of Texas Southwestern Medical Center, 5323 Harry Hines Blvd., Dallas, TX 75390, United States (e-mail: sam.barnett@utsouthwestern.edu).
\end{abstract}

J Neurol Surg Rep 2014;75:e33-e37.

\begin{abstract}
Keywords

- dermoid

- cyst

- infratemporal

- middle fossa

Background Intracranial dermoid cysts are rare tumors of congenital origin. We report a case of a large dermoid tumor arising in the infratemporal fossa (ITF) with erosion into the middle cranial fossa. After reviewing the literature, we believe this represents the first reported dermoid tumor of the ITF with extension into the middle cranial fossa.

Results A 21-year-old women presented with a large cystic mass involving the left infratemporal fossa and middle cranial fossa that was discovered following a motor vehicle collision. Neurologic examination was normal. The mass was resected through a frontotemporal extradural approach with endoscopic assistance. Imaging studies, gross findings, and histopathology were consistent with a dermoid tumor.

Conclusion This is the first report of a dermoid cyst arising in the ITF with extension into the middle cranial fossa. We suggest including dermoid tumor in the differential diagnosis of cystic abnormalities in this region. Complete resection of the cyst remains the preferred treatment with surgical approach guided by preoperative imaging.
\end{abstract}

\section{Introduction}

Intracranial dermoid cysts are rare tumors representing $<1 \%$ of head and neck tumors. They are believed to arise due to ectopic inclusion of epithelial cells in the course of neural tube closure during embryologic development. ${ }^{1}$ Dermoids tend to be midline lesions and contain dermal and epidermal elements including sebum, hair, and keratin. ${ }^{2}$ Rarely, these tumors have been reported in the middle cranial fossa, usually in the petrous apex or cavernous sinus. ${ }^{2,3}$ We report a case of a large extradural dermoid cyst arising in the infratemporal fossa (ITF) and eroding into the middle cranial fossa.

\section{Case Report}

A 21-year-old woman presented to our institution following an episode of syncope after a motor vehicle collision. Routine imaging studies demonstrated a large cystic lesion in the ITF. By history, the lesion was originally identified 7 years prior, but the patient was lost to follow-up. The patient reported a long history of frequent debilitating headaches, dizziness, and syncope. Neurologic examination revealed no cranial nerve deficits. Her past medical history was significant for surgical treatment of a cholesteatoma of her left mastoid at age 8 . Thin-cut computed tomography (CT) scan and magnetic resonance imaging (MRI) identified a heterogeneous mass centered within the left skull base that measured $4.7 \times 2.5 \times 3.4 \mathrm{~cm}$. It extended to the level of the anterior clinoid process and inferiorly between the lateral and medial pterygoid plates into the pterygoid fossa at the level of the pterygomaxillary fissure. The mass demonstrated restricted diffusion with areas of T1 shortening, suppressed on fat saturation images, consistent with a dermoid cyst. The tumor had no associated postcontrast enhancement and no edema received

May 8, 2013

accepted after revision

September 3, 2013

published online

December 12, 2013
DOI http://dx.doi.org/

10.1055/s-0033-1358795. ISSN 2193-6358.
@ 2014 Georg Thieme Verlag KG
Stuttgart · New York

License terms

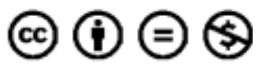




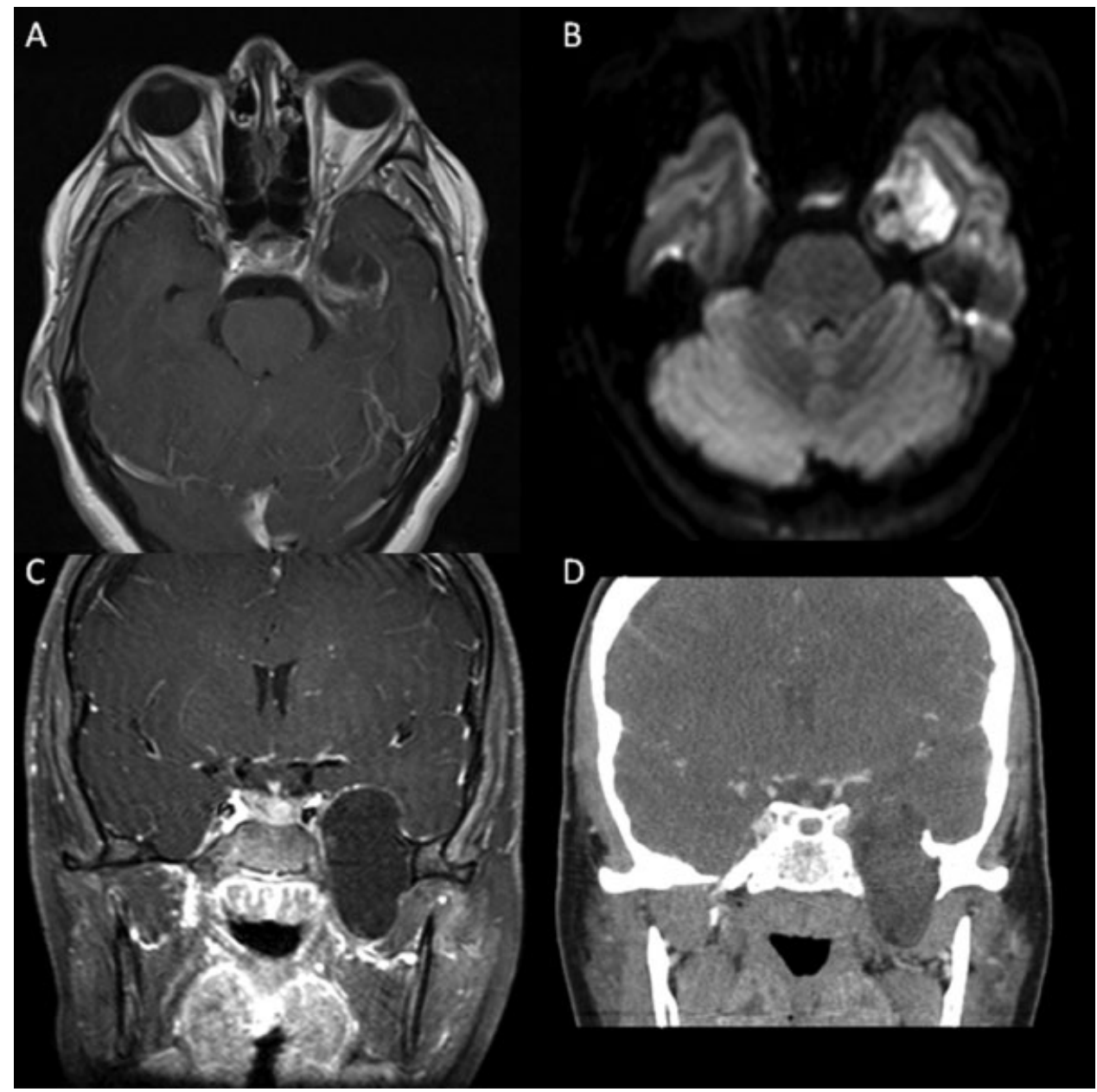

Fig. 1 Axial T1 with (A) gadolinium, (B) diffusion-weighted, (C) coronal T1 with gadolinium, and (D) coronal computed tomography.

in the adjacent brain parenchyma. Evidence of previous mastoidectomy was also noted (-Fig. 1).

A left frontotemporal craniotomy was performed, and an extradural approach was used to mobilize the medial temporal dura off the lateral wall of the cavernous sinus exposing the floor of the middle cranial fossa. A large mass was noted bulging through the defect in the floor of the middle fossa, anterior to V2 and V3. The tumor was entirely extradural and removed in a piecemeal fashion. Sloughed skin and hair were observed as the pieces were removed. The 30- and 70-degree endoscopes were inserted through the defect in the middle fossa floor and used to visualize additional tumor in the ITF. This allowed for endoscopically assisted resection of the remaining tumor using ring curettes. The only site of attachment of the tumor was noted in the ITF, and the middle fossa component appeared to represent a pushing margin (-Fig. 2). Histopathology demonstrated lamellar keratin consistent with either an epidermoid or dermoid cyst (-Fig. 3). However, visualization of hair during tumor removal confirmed the radiographic findings of dermoid cyst. The patient did well postoperatively with no new neurologic deficits. Follow-up imaging studies done $\sim 1$ month postoperatively demonstrated no evidence of recurrent or residual tumor (-Fig. 4).

\section{Discussion}

Epidermoid and dermoid cysts are squamous epitheliumlined inclusion cysts. ${ }^{4}$ Both epidermoid and dermoid cysts contain lamellar keratin and are lined by well-differentiated squamous epithelium. In contrast to epidermoid cysts, the lining of dermoid cysts contains adnexal structures such as hair follicles and apocrine, sebaceous, and sweat glands. ${ }^{5}$ Only 7\% of dermoids affect the head and neck, and they are frequently encountered in the lateral eyebrow, orbit, and nose. ${ }^{6}$ Dermoids are most commonly seen in women 20 to 36 years of age. ${ }^{1,5,7,8}$ Cranial dermoid cysts are estimated to occur 3 to 10 times less frequently as epidermoid tumors, and they comprise 0.04 to $0.7 \%$ of intracranial tumors. ${ }^{1,2}$

Dermoid cysts are benign and generally become symptomatic secondary to their mass effect on neural structures. ${ }^{5}$ Clinically, they often present with a protracted course rather than an acute decline. ${ }^{9}$ The presentation of intracranial dermoids varies depending on cyst location, although common symptoms include focal neurologic deficit, headache, or meningitis. ${ }^{10,11}$ Less common presentations include seizures, hydrocephalus, visual field defects, exophthalmos, and oculomotor palsy. Sudden death has also been reported in the case of spontaneous rupture. . $^{2,13}$ 

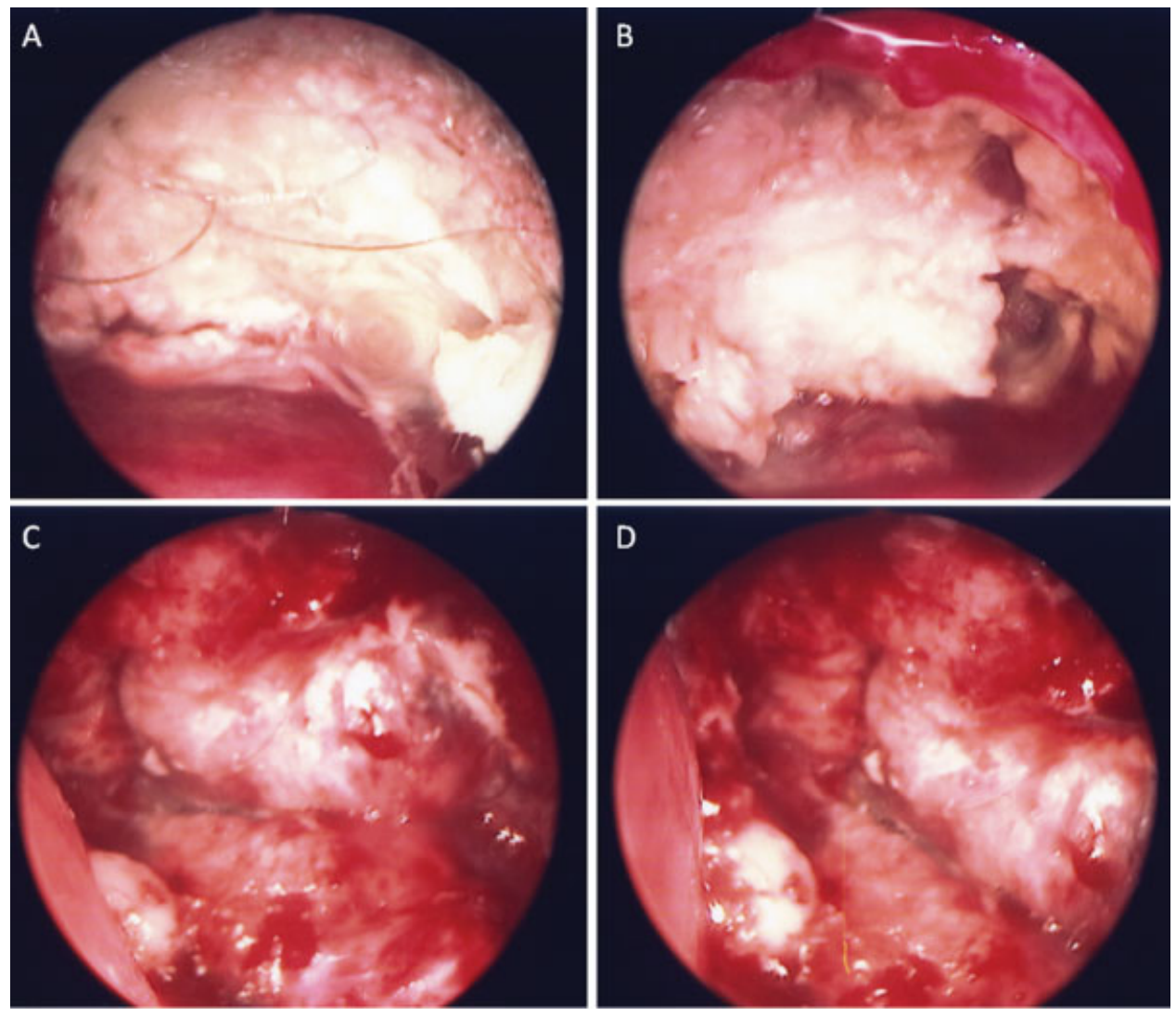

Fig. 2 (A-D) Endoscopic views of the tumor and its origin through the bony defect in the middle fossa floor demonstrating progressive resection of the tumor.

Dermoids tend to be midline in location with extradural dermoids reported in the diploë of the anterior fontanelle, posterior fossa, or orbital regions. ${ }^{1,2,10,11}$ Multiple dermoid cysts of the head and neck are uncommon but have been reported. ${ }^{14}$ The few reported dermoid tumors in the middle cranial fossa have been usually located between layers of the lateral wall of the cavernous sinus. ${ }^{2,10,15,16}$ The one previ-

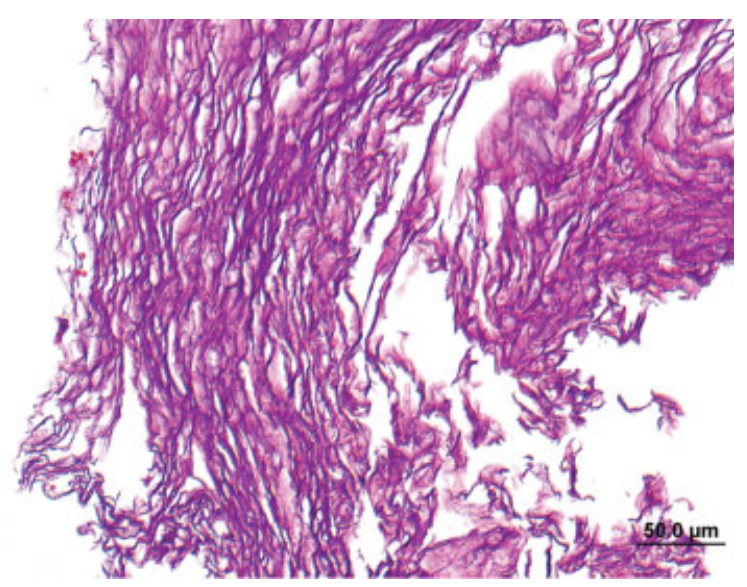

Fig. 3 Lamellar keratin, consistent with an epidermoid or dermoid cyst. It was not possible to distinguish between the two histologically because no viable epithelium was present in the specimen submitted for pathology. (Hematoxylin and eosin; original magnification $\times 200$ ). ously reported case of a dermoid involving the ITF presented with rapidly growing facial swelling in a 17 -year-old girl. ${ }^{6}$

Tumors arising in the ITF can remain asymptomatic until they are quite large, producing symptoms late in the clinical course. When including all intracranial dermoids, the average duration of symptoms prior to diagnosis is 8.5 years. ${ }^{5,6}$ Dermoid cysts grow slowly and expand through glandular secretion or epithelial desquamation. ${ }^{1}$ As the cyst grows, it follows the path of least intracranial resistance, particularly the subarachnoid space. ${ }^{8}$ Dermoid cysts are typically round or multilobular with a firm capsule. The contents of the cyst generally consist of a soft, oily mass with keratin debris, and they often contain hair. ${ }^{6}$ Dermoids are often more solid than epidermoids and therefore less likely to insinuate between neurovascular structures, but they generally produce greater local mass effect. ${ }^{5}$ Dermoid tumors do frequently adhere to vascular and nervous structures, however. ${ }^{1}$

Imaging studies remain essential in diagnosing these lesions. The differential diagnosis includes epidermoid cysts, arachnoid cysts, cystic gliomas, lipomas, teratomas, and craniopharyngiomas. In contrast to epidermoid cysts that resemble cerebrospinal fluid on MRI and CT scan, dermoid cysts have heterogeneous imaging characteristics and contain fat. ${ }^{17}$ CT scan provides data about the size and extent of the tumor along with its location including relationship to adjacent bone. In our case, the dermoid was extradural and displayed well-defined osseous erosion, reported previously 


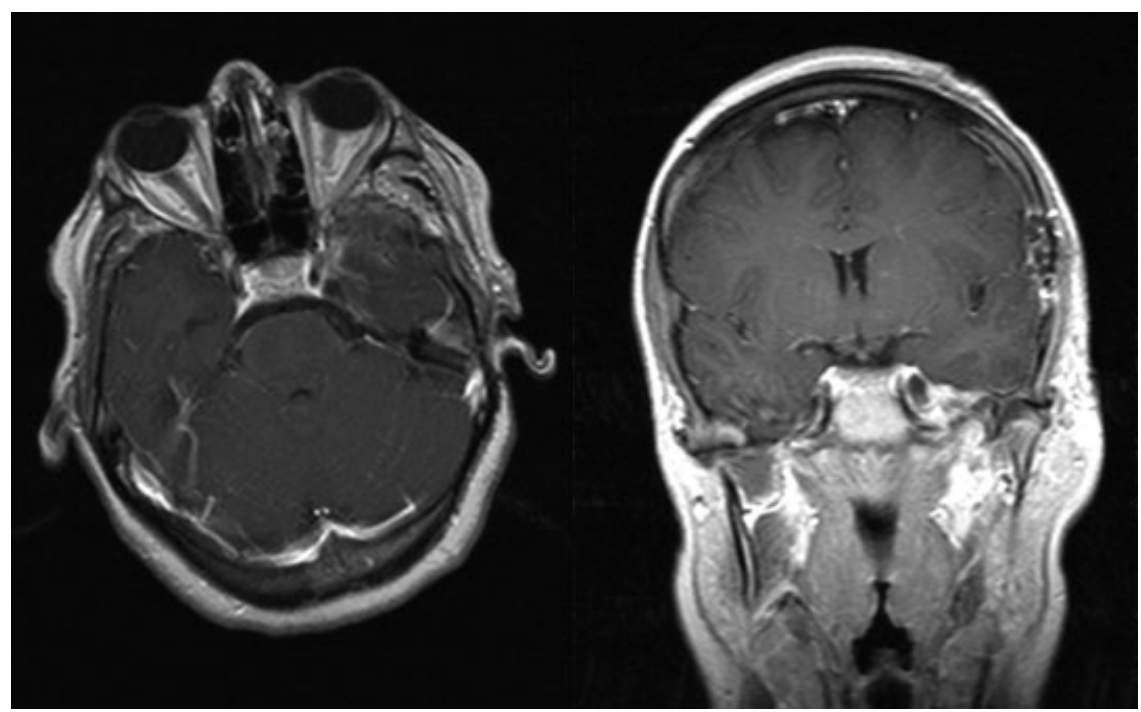

Fig. 4 Postoperative axial (left) and coronal (right) T1 postcontrast magnetic resonance imaging scans demonstrating complete resection of the lesion.

by others. ${ }^{1,2,18} \mathrm{CT}$ reveals a strongly hypodense lesion due to the high fat content, and most do not enhance, although enhancing capsules have been reported. ${ }^{2,10,13}$ MRI is valuable in determining the lesion's relationship to neighboring neurovascular structures. ${ }^{6}$ Dermoid cysts are nonenhancing with most of them demonstrating hyperintensity on T1-weighted images and heterogeneous signal intensity on T2-weighted sequences determined by the water content, sebum, and hair follicles in the cyst. ${ }^{2,12,17,19}$ Diffusion-weighed imaging frequently demonstrates areas of hyperintensity in the solid keratin-rich portions of the lesion. They also typically contain areas of T1 shortening that suppress on fat-saturated images. $^{12}$ With cyst rupture, fat droplets can be seen in the subarachnoid space and ventricular system with diffuse meningeal enhancement from chemical meningitis. $9,17,20$ Surgical resection remains the treatment of choice, although tumors involving both the infratemporal fossa and the middle cranial fossa are uncommon and can pose significant challenges for neurosurgeons. ${ }^{21}$ With improvements in microneurosurgical techniques, total resection is often achieved by many authors and is believed to decrease both postoperative chemical meningitis and tumor recurrence risk. ${ }^{8,11,16,22}$ The resection of dermoid cysts begins with opening the capsule and then debulking the cyst contents followed by microsurgical dissection of the capsule from adjacent neurovascular structures. ${ }^{7,8,23}$ When these lesions adhere to neurovascular structures, the benefits of complete capsule removal must be weighed against the risks of new neurologic deficit. Because these lesions typically have a benign natural history, subtotal resection is recommended in these situations. ${ }^{2,7,8,19}$ Radiation and chemotherapy have not demonstrated efficacy in the management of dermoid cysts and are therefore not recommended., 5

The prognosis of dermoids in the head and neck is favorable. Malignant transformation is rare and has been reported very few times. ${ }^{19}$ The three reports have described transformation to squamous cell carcinoma from intracranial der- moid cysts in two separate cases as well as from a sublingual dermoid cyst. ${ }^{19,20,24-26}$

In our patient's case, it is unclear how the history of cholesteatoma of the left mastoid relates to the ITF lesion. Cholesteatoma is a clinical term used for an epidermoid cyst involving the temporal bone. It is possible that two separate lesions arose simultaneously secondary to problems during embryologic development. The simplest explanation may be that residual tumor in the petrous apex could have spread to the ITF. It is unclear whether the tumor in our case arose in the ITF or within the bone of the middle fossa and spread. At the time of surgery, however, the tumor appeared to originate in the ITF and did not have any obvious communication with the petrous portion of the temporal bone.

\section{Conclusions}

We believe this is the first report of a dermoid cyst arising in the ITF with extension into the middle cranial fossa. The tumor was successfully removed, and the patient is now 18 months out from surgery without residual or recurrent tumor. We suggest including dermoid tumor in the differential diagnosis of cystic abnormalities in this region. Complete resection of the cyst remains the preferred treatment. Surgical planning is guided by preoperative imaging.

\section{Disclaimer}

The authors have no conflicts of interest or financial support to disclose.

\section{References}

1 Rubin G, Scienza R, Pasqualin A, Rosta L, Da Pian R. Craniocerebral epidermoids and dermoids. A review of 44 cases. Acta Neurochir (Wien) 1989;97(1-2):1-16 
2 Akdemir G, Dağlioğlu E, Ergüngör MF. Dermoid lesion of the cavernous sinus: case report and review of the literature. Neurosurg Rev 2004;27(4):294-298

3 Behnke EE, Schindler RA. Dermoid of the petrous apex. Laryngoscope 1984;94(6):779-783

4 Smirniotopoulos JG, Chiechi MV. Teratomas, dermoids, and epidermoids of the head and neck. Radiographics 1995;15(6): 1437-1455

5 Gumerlock M. Epidermoid, dermoid and neurenteric cysts. In: Winn HR, ed. Youmans Neurological Surgery. Vol 1. 5th ed. Philadelphia, PA: WB Saunders; 2004:1223-1230

6 Uppal HS, D'Souza AR, De R, Irving RM. Dermoid cyst of the infratemporal fossa. J Laryngol Otol 2002;116(2):150-152

7 Lunardi P, Missori P. Supratentorial dermoid cysts. J Neurosurg 1991;75(2):262-266

8 Yaşargil MG, Abernathey CD, Sarioglu AC. Microneurosurgical treatment of intracranial dermoid and epidermoid tumors. Neurosurgery 1989;24(4):561-567

9 Sanchez-Mejia RO, Limbo M, Tihan T, Galvez MG, Woodward MV, Gupta N. Intracranial dermoid cyst mimicking hemorrhage. Case report and review of the literature. J Neurosurg 2006;105(4, Suppl):311-314

10 Ammirati M, Delgado M, Slone HW, Ray-Chaudhury A. Extradural dermoid tumor of the petrous apex. Case report. J Neurosurg 2007; 107(2):426-429

11 Gormley WB, Tomecek FJ, Qureshi N, Malik GM. Craniocerebral epidermoid and dermoid tumours: a review of 32 cases. Acta Neurochir (Wien) 1994;128(1-4):115-121

12 Orakcioglu B, Halatsch ME, Fortunati M, Unterberg A, Yonekawa Y. Intracranial dermoid cysts: variations of radiological and clinical features. Acta Neurochir (Wien) 2008;150(12):1227-1234; discussion 1234

13 Brown JY, Morokoff AP, Mitchell PJ, Gonzales MF. Unusual imaging appearance of an intracranial dermoid cyst. AJNR Am J Neuroradiol 2001;22(10):1970-1972

14 Perry JD, Tuthill R. Simultaneous ipsilateral temporal fossa and orbital dermoid cysts. Am J Ophthalmol 2003;135(3):413-415
15 North KN, Antony JH, Johnston IH. Dermoid of cavernous sinus resulting in isolated oculomotor nerve palsy. Pediatr Neurol 1993; 9(3):221-223

16 Nakagawa K, Ohno K, Nojiri T, Hirakawa K. Interdural dermoid cyst of the cavernous sinus presenting with oculomotor palsy: case report [in Japanese]. No Shinkei Geka 1997;25(9):847-851

17 Osborn AG, Preece MT. Intracranial cysts: radiologic-pathologic correlation and imaging approach. Radiology 2006;239(3): 650-664

18 Akhaddar A, Jiddane M, Chakir N, El Hassani R, Moustarchid B, Bellakhdar F. Cerebellar abscesses secondary to occipital dermoid cyst with dermal sinus: case report. Surg Neurol 2002;58(3-4): 266-270

19 Al-Muhaimeed HS, Abdelwahed HY, Elgamal EA, Alokby GM, Binnasser AM, Ashraf MM. Extradural dermoid cyst of mastoid bone: a case report. Case Rep Otolaryngol 2012;2012:548340

20 El-Bahy K, Kotb A, Galal A, El-Hakim A. Ruptured intracranial dermoid cysts. Acta Neurochir (Wien) 2006;148(4):457-462

21 Bao S, Ni S, Zhang J, et al. Treatment of lesions involving both the infratemporal fossa and middle skull base. Surg Neurol 2006;66 (Suppl 1):S10-S17; discussion S17

22 Sturiale CL, Mangiola A, Pompucci A, D'Ercole M, Di Muro L, Anile C. Interdural giant dermoid cyst of the petrous apex. J Clin Neurosci 2009;16(11):1498-1502

23 Liu JK, Gottfried ON, Salzman KL, Schmidt RH, Couldwell WT. Ruptured intracranial dermoid cysts: clinical, radiographic, and surgical features. Neurosurgery 2008;62(2):377-384; discussion 384

24 Kobayashi T, Kuchiwaki H, Inao S, Nakashima N. A squamous cell carcinoma originated from intracranial dermoid cyst. Neurochirurgia (Stuttg) 1993;36(1):26-29

25 Tsugu H, Fukushima T, Hayashi S, Iwaasa M, Matsuda T. Squamous cell carcinoma arising in an intracranial dermoid cyst-case report. Neurol Med Chir (Tokyo) 2001;41(4):213-216

26 Devine JC, Jones DC. Carcinomatous transformation of a sublingual dermoid cyst. A case report. Int J Oral Maxillofac Surg 2000;29(2): $126-127$ 